\title{
Los soportes textiles de pintura de caballete en México, siglos XVII-XIX. Aportaciones históricas tras su restauración
}

\author{
Rita Sumano González
}

Resumen: El presente artículo aborda la forma en que ciertos lienzos textiles fueron usados como soportes de pintura de caballete en México durante los siglos XVII al XIX. Se llevó a cabo un estudio usando como fuente primaria doscientos informes de trabajo de pinturas que habían sido restauradas por el Seminario Taller de Restauración de Pintura de Caballete de la Escuela Nacional de Conservación, Restauración y Museografía en México (STRPC-ENCRyM-INAH). Los registros de técnica de factura de los soportes se organizaron de acuerdo a una ficha de análisis textil y se vertieron en una base de datos, para después interpretarlos utilizando estadística descriptiva. Los resultados del análisis estadístico orientaron la investigación histórica, que se sirvió de fuentes vivas, materiales, bibliográficas y documentales. De esta investigación se desprendieron datos relevantes sobre la forma en que los lienzos fueron usados como soportes de pintura de caballete lo que puede contribuir a su estudio y a una mejor conservación de las pinturas.

Palabras clave: Soporte textil; Caballete; México.

\section{Os suportes têxteis na pintura de cavalete no México, nos séculos XVII-XIX. Contribuições históricas dos seus restauros.}

O presente artigo aborda a forma como certos tecidos foram usados como suporte na pintura de cavalete, no México, durante os séculos XVII a XIX. Como fonte primária, utilizaram-se duzentos relatórios de pinturas que haviam sido restauradas pelo Seminário Oficina de Restauro de Pintura de Cavalete da Escola Nacional de Conservação, Restauro e Museologia, do México (STRPC-ENCRyM-INAH). Os registos da técnica de manufactura dos suportes foram compilados de acordo com uma ficha de análise dos têxteis, e foram reunidos numa base de dados, para depois serem interpretados através de estatística descritiva. Os resultados da análise estatística orientaram a investigação histórica, que se baseou em fontes vivas, materiais, fontes bibliográficas e documentais. Desta investigação resultaram relevantes dados sobre a forma como os tecidos foram utilizados como suporte na pintura de cavalete, podendo contribuir para o seu estudo e para uma melhor conservação das pinturas.

Palabras- chave: Suporte textil; Cavalete; México.

\section{Canvas supports on Mexican paintings, $17^{\text {th }}-19^{\text {th }}$ century. Historical contributions after restoration}

\begin{abstract}
This article examines the way in which certain canvases were used as supports for Mexican paintings from the 17th to the 19th century. This work used as a primary source of information two hundred registers of paintings that have been restored in the Workshop-Seminar for Canvas Painting Restoration from the National School of Restoration, Conservation and Museography from the National Institute of Anthropology and History (STRPC-ENCRyM-INAH). These registers were based on a set of criteria for textile analysis and the results were held in a data bank. Descriptive statistics were used to interpret the data. The results of the statistical analysis guided the historical research, which used personal, material, bibliographical and documentary sources of information. This research revealed relevant data concerning the origin, the material composition and facture of the canvas and could contribute significantly to their study and preservation of the paintings.
\end{abstract}

Key words: Canvas supports; Paintings; Mexico. 


\section{Introducción}

La pintura de caballete ha sido una de las expresiones artísticas más socorridas en México desde la conquista española, modificándose a través del tiempo tanto estética, como iconográfica y materialmente. Sin embargo, aun hasta hace poco, se ha estudiado la imagen en menoscabo de la materialidad del objeto, provocando un desequilibrio en el conocimiento que tenemos sobre las pinturas. Por tal razón, se decidió enfocar esta investigación en la técnica de factura de los soportes textiles de la pintura de caballete mexicanas de los siglos XVII al XIX, para así ayudar a entender e interpretar la evidencia material que contienen.

En el ámbito de la conservación, a la base o sustento sobre el que se realiza una pintura se le llama soporte, siendo el textil la forma más frecuente de sustentar la pintura de caballete mexicana. Si bien los soportes textiles suelen presentar estructuras particulares que los caracterizan según las distintas épocas y escuelas artísticas, existen pocos estudios detallados a este respecto, entre ellos los de Rolf, Koller y Bruquetas (Rolf 1984; Koller 1984; Bruquetas 2007), que se enfocan en la Edad Media, la pintura contemporánea y los Siglos de Oro español, respectivamente.

El uso y abuso del método de rentelaje o reentelado en la restauración, ha despertado el debate sobre la conservación de las características originales de los soportes textiles. Tal interés se ve reflejado desde 1974 en diversos congresos internacionales; el primero de ellos, el International Symposium of Comparative Lining Techniques, propuso una moratoria en este proceso hasta que no se determinaran sus efectos sobre las obras y la efectividad de los nuevos materiales utilizados. El año siguiente, durante el congreso del ICOM, se decide suspender los rentelajes durante un mínimo de tres años y se designa un comité encargado de evaluar el proceso, llamado Strechers and Relining (Perez 2003: 94). En 1995, se lleva a cabo en el United Kingdom Institute of Conservation la conferencia Lining and Backing: the Support of Paintings, Paper and Textiles, donde se compara y evalúa el proceso en soportes textiles y de papel. Diez años más tarde, se lleva a cabo el congreso Interim Meeting: International Conference on Painting Conservation. Canvases: Behavior, Deterioration \& Treatment, donde se discute el tema de los soportes textiles, centrándose principalmente en los procesos de restauración que los afectan. Allí, Konrad Laudenbacher menciona la importancia de indagar en los soportes textiles como parte de la evidencia material que nos deja la pintura, señalando la necesidad de hacer estudios exhaustivos a este respecto (Laudenbacher 2005:111-118).

El estado del soporte es fundamental para la conservación de las pinturas y, muchas veces, las alteraciones que aparecen en la superficie son efectos provenientes de problemas en él. Los procesos de restauración inciden directamente no sólo sobre la imagen, sino también sobre la materialidad del objeto pudiendo modificar sus características de manera irreversible. Al entender la importancia de la evidencia contenida en los soportes textiles de las pinturas de caballete, se comprenden los alcances de una desacertada intervención de restauración que pudiera modificar las características originales de la obra. Un análisis y registro adecuado del reverso de las obras ayudará a proteger la valiosa evidencia que contienen los soportes, y a su vez, mejorará la caracterización del deterioro presente, y, por tanto, ayudará a establecer pautas para llevar a cabo métodos de limpieza, refuerzos y montajes adecuados.

\section{Metodología}

El estudio está basado en los informes de trabajo elaborados por los estudiantes de la Licenciatura en Restauración que cursaron el Seminario-Taller de Restauración de Pintura de Caballete de la Escuela Nacional de Conservación, Restauración y Museografía del Instituto Nacional de Antropología e Historia (STRPC-ENCRyM-INAH) entre los años 1997 y 2009. De dichos informes se extrajo un 
número total de cuadros de acuerdo con los siguientes criterios de inclusión de muestra: que las pinturas hubieran sido intervenidas y registradas en el STRPC; que tuvieran soporte textil; que se tratara de pintura producida en territorio mexicano; que pertenecieran a los siglos XVII, XVIII o XIX; que no existieran dudas respecto del siglo en el que fueron pintadas; que las intervenciones anteriores al momento del informe no hubieran modificado irreversiblemente los datos del soporte; que el informe en el que se encontraron registrados los datos fuera confiable y estuviera respaldado por pruebas científicas (observación bajo microscopio, pruebas a la gota, análisis materiales e instrumentales, etcétera).

Para sistematizar la información, se realizó una base de datos electrónica y se cuantificó la incidencia de las características de los soportes textiles según variables establecidas en una ficha de análisis textil, que aborda lo relativo a la conformación del tejido y su uso como soporte de pintura de caballete.

En un artículo anterior, hablé sobre la técnica de factura de los lienzos utilizados como soportes de pintura de caballete y allí se abordaron las variables relativas a la conformación del hilo y del tejido, como torsión, ligamento textil, densidad de hilos y caracterización de la fibra, entre otras (Sumano 2011: 42-50). En el presente artículo, sin embargo, se hará énfasis en ese segundo momento en que estos mismos lienzos fueron usados como soportes de pinturas: se analizan las variables relativas a las dimensiones del soporte, formatos, formas de montaje al bastidor, marcaje y huellas de reutilización.

Con las variables establecidas, se realizó una estadística cuantitativa y descriptiva (porcentajes, media, mediana, rangos, desviación estándar y correlaciones), utilizando el programa Excel $^{\varpi}$ y OriginPro $8 \mathrm{SRO}^{\oplus}$. De los 352 informes revisados originalmente, 152 se excluyeron por no cumplir con los criterios de inclusión de muestra, y los 200 cuadros restantes constituyeron el tamaño de muestra o "N". En total, se examinaron 27 registros del siglo XVII, 136 del XVIII y 37 del XIX. Los resultados del análisis estadístico ayudaron a orientar la investigación histórica que se sirvió de fuentes vivas, materiales, bibliográficas y documentales.

\section{Resultados}

A continuación se exponen los resultados más relevantes de esta investigación. Las características del tejido en los lienzos de los siglos XVII al XIX, se describen brevemente para contextualizar al lector.

\section{Características del tejido}

De acuerdo con nuestro análisis estadístico, los soportes que corresponden al siglo XVII son principalmente tafetanes de lino con densidades de tejido de $11 \times 12$ hilos $/ \mathrm{cm}^{2}$; mientras que en el siglo XVIII la densidad de tejido aumenta a $12 \times 13$ hilos $/ \mathrm{cm}^{2}$-ver glosario-. Los orillos encontrados en los lienzos de ambos siglos, indican un ancho de tela no mayor a los $113 \mathrm{~cm}$. Los soportes de pinturas pueden estar compuestos por varios lienzos y/o partes de ellos, y pueden combinarse varias fibras en un mismo soporte de pintura. Tanto en el siglo XVII como en el XVIII, se utilizaron fibras mexicanas endémicas y mezclas locales de fibras en las costuras de unión de los lienzos (Sumano 2010: 4-28)

En su mayoría, los soportes textiles del siglo XIX que se analizaron resultaron ser también tafetanes de lino, pero en este siglo se incorporan nuevos ligamentos textiles y nuevas fibras como el yute o el algodón. Los lienzos utilizados en este siglo se puede dividir en dos grandes campos: manuales e 
industriales. Los primeros muestran hilado manual, nudos y baja densidad de tejido, mientras que los segundos presentan una alta densidad de tejido (media de $17 \times 18$ hilos $/ \mathrm{cm}^{2}$ ), hilos regulares, tejidos cerrados, delgados y homogéneos (Sumano 2011: 42-50).

El lino es la fibra más presente en los lienzos de todos los siglos estudiados, (95\% de los casos en los siglos XVII y XVIII y $60 \%$ en el siglo XIX).

\section{Formatos}

El $85 \%$ de los lienzos analizados del siglo XVII fue ejecutado en un formato rectangular, el $11 \%$ en uno mixtilíneo y sólo un cuadro -representativo del 3.7\%- fue hecho en formato circular (tondo). Hacia el siglo XVIII se mantiene la predominancia de los cuadros rectangulares, sin embargo se introducen cuadros ochavados, ovales y compuestos que, juntos, representan un $15 \%$ del total de las obras analizadas.

La forma más frecuente de montar los lienzos al bastidor durante el siglo XVII fue pegarlos con cola de origen animal. En el siglo XVIII este porcentaje disminuye a $51.32 \%$, y en el siglo siguiente se reduce a $42.86 \%$. El uso de elementos metálicos como clavos -solos o auxiliados con adhesivo-, aumenta conforme transcurren los siglos. Se pudo observar que aquéllos lienzos que carecen de pestañas que los sostienen al bastidor son los de formatos mixtos o rectangulares. En los formatos mixtos este distintivo podría estar evidenciando una técnica de factura particular que buscaba adaptar los lienzos a cualquier tipo de forma. Por un lado se lavaba y preparaba el soporte textil y, a continuación, se colocaba alineado sobre una superficie lisa -posiblemente todavía húmedo para que al secar se tensara un poco la tela-. Por otro lado, se encolaba el canto de frente del bastidor y, estando el adhesivo aún mordente, se volteaba sobre el soporte extendido y algo húmedo. Posteriormente, se dejaba secar y simplemente se cortaba el contorno sobrante del soporte con una navaja dejando un cuadro sin pestañas y adecuado perfectamente a la forma del bastidor [Figura $1]$.
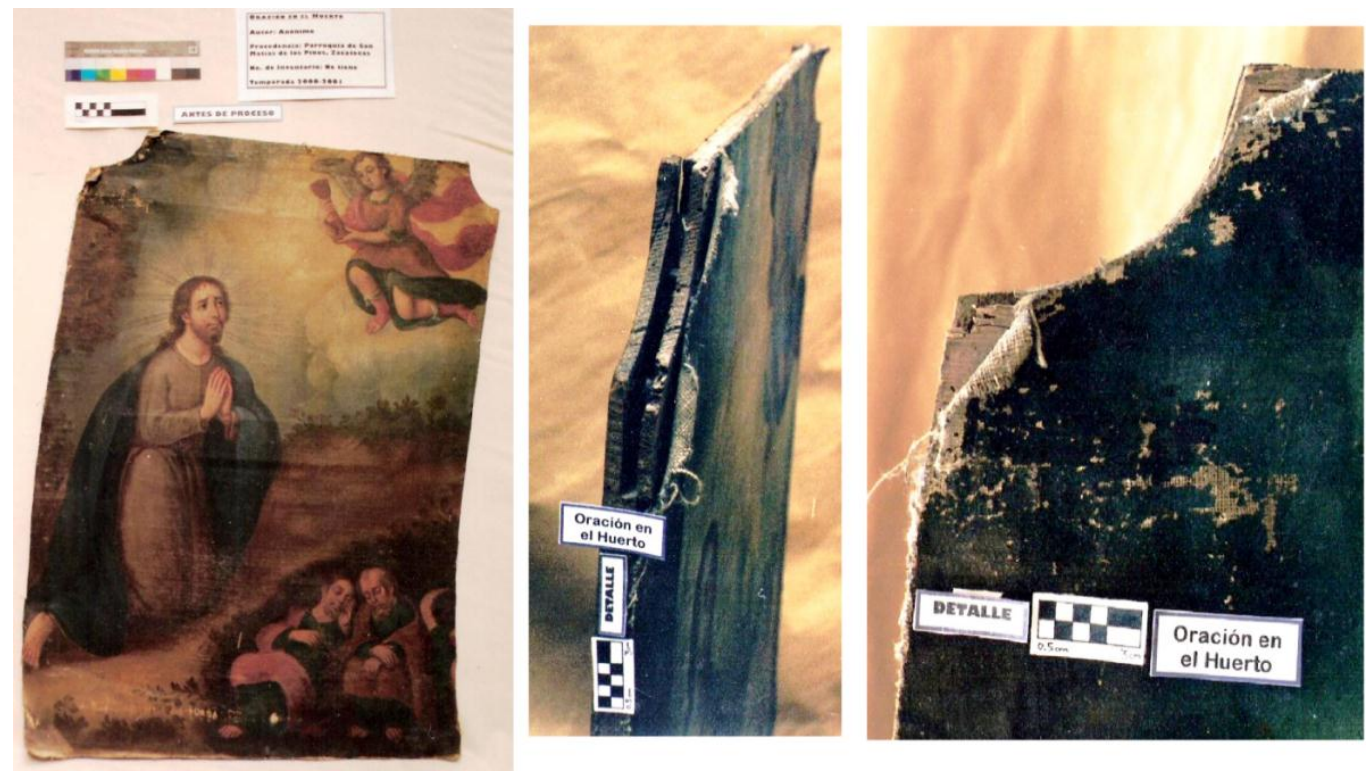

Figura 1. La Oración en el huerto. Pintura en formato mixto montada en un lienzo sin pestañas. Proveniente de La Parroquia de San Matías en Pinos, Zacatecas (Tomado de Dávila Lorenzana: 2001. Cortesía: Archivo del STRPC-ENCRYM). 


\section{Dimensiones y extensiones del soporte}

La media del alto de las pinturas analizadas del siglo XVII es de $139.64 \mathrm{~cm}$, en el siglo XVIII aumenta a 163.66 y en el siglo XIX se reduce a $114.16 \mathrm{~cm}$. La misma tendencia se repite en el ancho y por tanto en la superficie total de los lienzos [Figura 2].

\begin{tabular}{|l|l|l|l|l|l|l|}
\hline Siglo & $\mathbf{N}$ & Media & $\begin{array}{l}\text { Desviación } \\
(\mathbf{\pm})\end{array}$ & estándar & Rango & Mediana \\
\hline Alto & & & & & & \\
\hline
\end{tabular}

\begin{tabular}{|l|l|l|l|l|l|l|}
\multicolumn{2}{|l}{ Ancho } \\
\multicolumn{7}{|l|}{} \\
\hline XVII & 27 & 99.65 & 36.15 & 49 & 212 & 100 \\
\hline XVIII & 136 & 117.76 & 68.20 & 25.8 & 633 & 106 \\
\hline XIX & 37 & 85.24 & 36.79 & 42.5 & 210 & 70.6 \\
\hline
\end{tabular}

Figura 2. Alto y ancho (en centímetros) de los cuadros en los siglos XVII, XVIII y XIX.

En estadística descriptiva, la media corresponde a la suma de todos los datos dividida por el número total de ellos. Es lo que se conoce como "promedio". Se denomina rango estadístico (R) al intervalo de menor tamaño que contiene a los datos. Permite obtener una idea de la dispersión de los mismos. La mediana es aquel valor que ocupa el lugar central, de modo que la mitad de los casos queda por debajo de ese valor y la otra mitad por encima.

Debido a que las piezas que componen los soportes pueden ser lienzos completos o solo fragmentos de éstos, se ha decido llamarlos partes que componen al soporte, refiriéndose genéricamente tanto a los fragmentos como a los lienzos enteros. En el siglo XVII, el número de partes que componen un soporte fue predominantemente uno; mientras que en el siglo XVIII este número aumenta inclusive hasta 18 partes, considerando que las dimensiones de los soportes son mayores en este siglo. Durante el siglo XIX los soportes vuelven a estar hechos de una sola parte.

Para unir los lienzos fue necesario utilizar adhesivos y pespuntes. Durante el siglo XVII la forma más utilizada fue la costura simple, presente en un $50 \%$ de los casos. Le sigue la costura enrollada con una presencia de $25 \%$ y, por último, el empalme de telas presente en un $12.5 \%$ de los casos [Figura 3]. En los siglos siguientes esta tendencia se mantiene. Para unir los lienzos se usaron hilos de diferentes fibras: en el siglo XVII se presentan fibras de agave (12.5\% de nuestra muestra) y de seda (12.5\%); en el resto de los casos no hay registros. Para cuadros del siglo XVIII encontramos que $6.5 \%$ 
son de fibras de yute, $1.61 \%$ de algodón con seda, $3.23 \%$ de agave y $4.84 \%$ de lino. El resto de los informes no lo especifica.
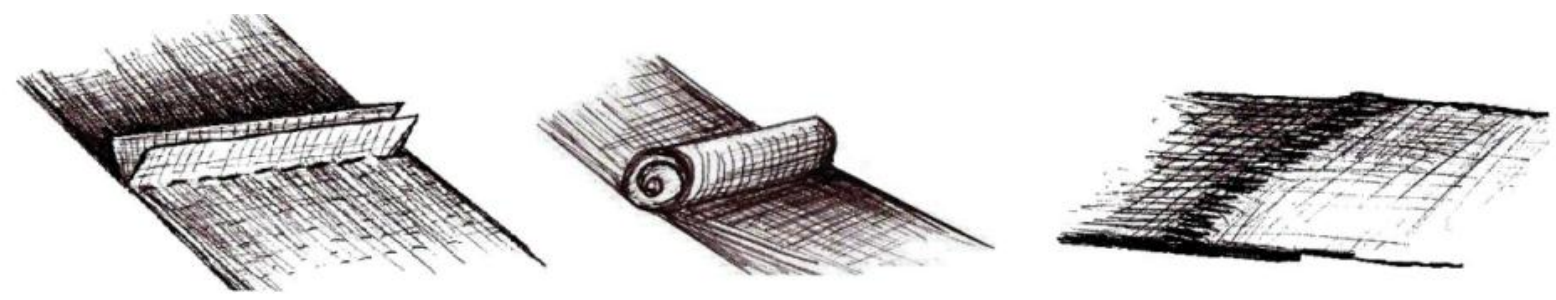

Figura 3. Costura simple, izquierda. Costura enrollada (al centro). Empalme de telas (derecha). Dibujos: Autor. Nota: para más información véase el Glosario.

Para compensar el cambio de textura provocado por la costura de unión, los pintores novohispanos la cubrieron por el anverso con una tira delgada de papel que homogeneizaba la superficie. La totalidad de los cuadros del siglo XVII que cuentan con más de una parte en su soporte, presentan esta tira de papel que disimula la unión de las telas. Durante el siglo XVIII, $72.58 \%$ de los cuadros cuentan con esta característica, mientras que $8.06 \%$ prescinde de ella. Sabemos que en el XIX la práctica se mantiene en un $22.22 \%$ de los cuadros, sin embargo faltan registros para más del $60 \%$ de las obras analizadas, por lo que no ha sido posible derivar conclusiones a este respecto.

\section{Pastas originales}

La aplicación de lo que los restauradores mexicanos llaman pastas originales, se refiere a un recurso que utilizaron los pintores para extender la superficie pictórica más allá de los límites del lienzo. Para esto, el lienzo se pegaba al canto frontal del bastidor y la ampliación se rellenaba con el mismo material con el que se elaboraba la base de preparación, consiguiendo así el mismo grosor de toda la superficie a pintar, como se muestra en la [Figura 4].
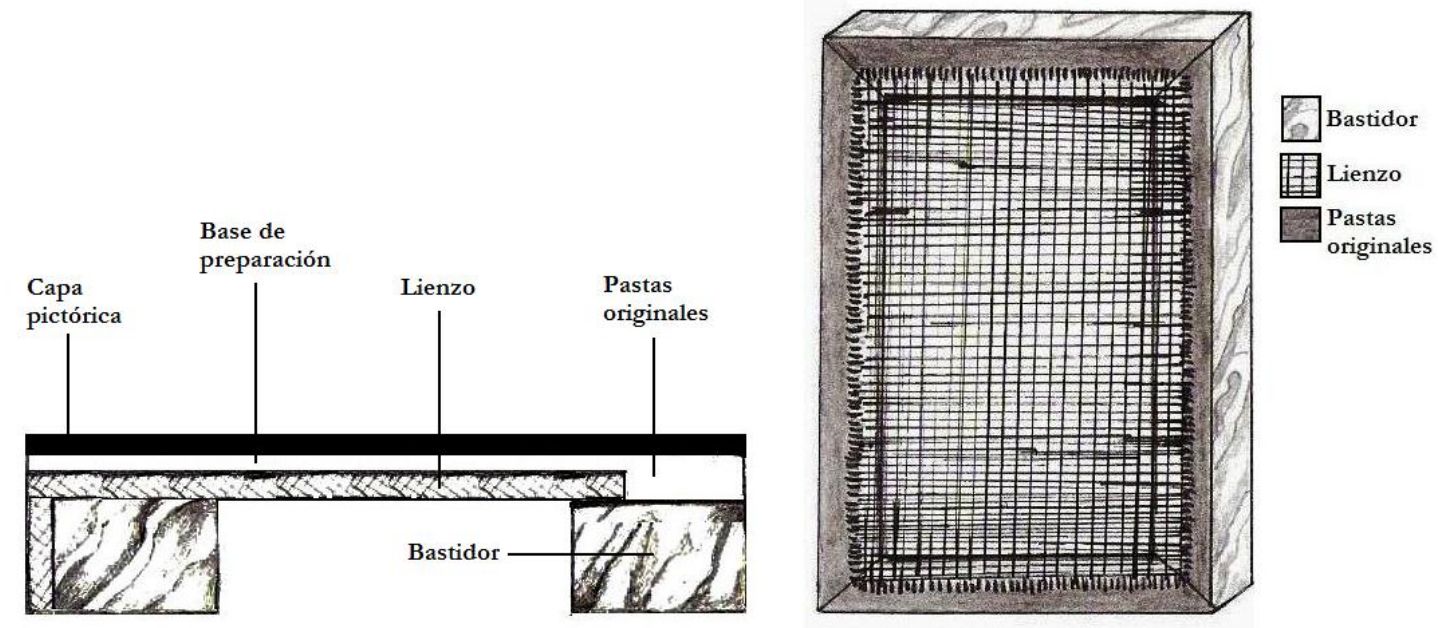

Figura 4. Esquema de pastas originales, vista transversal (izquierda) y esquema de vista frontal (derecha). Dibujos: Autor 
Esta característica está presente en un 15\%, $12.5 \%$ y $5.41 \%$ de los lienzos del siglo XVII, XVIII y XIX, respectivamente. Cuando se recurrió al uso de pastas, éstas cubrían por lo general 3 ó 4 elementos del bastidor, lo que hace pensar que se trataba de una forma más de compensar la escasez de lienzos.

\section{Los agujeros pareados}

En un $15 \%$ y $13 \%$ de los lienzos analizados de los siglos XVII y XVIII, respectivamente, se puede apreciar lo que los restauradores mexicanos llaman agujeros pareados. Estos agujeros, que pueden correr de cabezal a cabezal, de larguero a larguero o describiendo una fila inclinada, varían en número desde las decenas hasta superar la centena. No atraviesan ni parecen estar incidiendo de manera intencional sobre la capa pictórica o la base de preparación, lo que indica que los lienzos fueron agujerados en forma previa a su montaje sobre el bastidor. Por otro lado, se puede inferir que estos agujeros son evidencia de una actividad llevada a cabo en la época colonial, puesto que ningún lienzo del siglo XIX posee esta característica.

Tras la observación de esquemas y fotografías pertenecientes a 163 cuadros con agujeros pareados -27 del siglo XVII y 136 del siglo XVIII-, se ha podido distinguir que dichos agujeros están dispuestos con una simetría en espejo y siguen patrones de disposición con líneas rectas y ángulos de $90^{\circ}$, como se muestra en la figura 5.

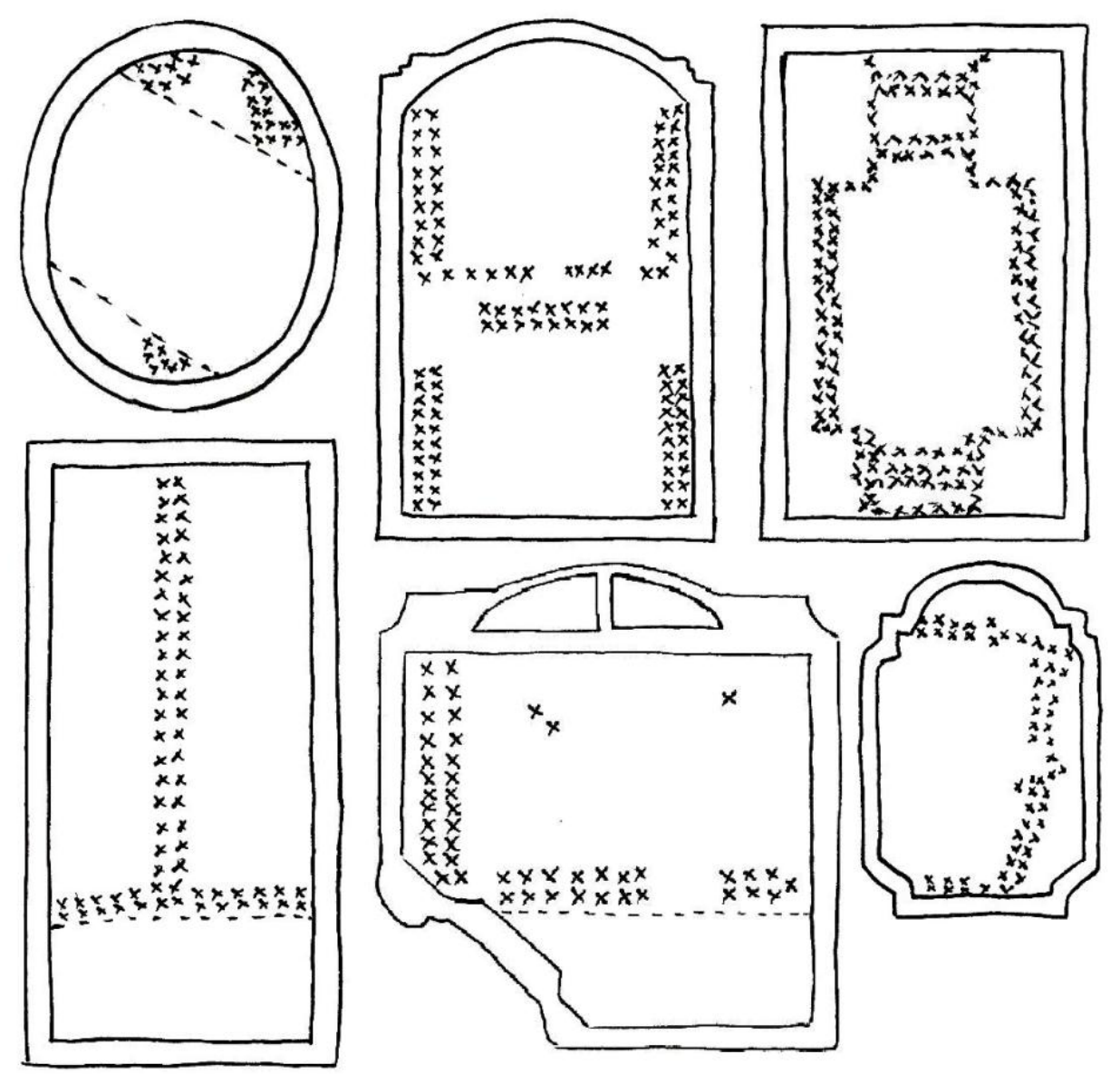

Figura 5. Disposición de los agujeros pareados en algunos cuadros que conforman la base de datos. Dibujo: Autor. 
Relacionados con estos agujeros se puede observar una serie de soluciones que el pintor usaba para taparlos y crear una superficie lisa en el lienzo, como rellenarlos con pastas, fibras, base de preparación con cargas, papel y parches de tela.

\section{Inscripciones y sellos}

Se utiliza el término general de inscripciones para denominar a las palabras, los números, las letras, signos ilegibles y sellos inscritos en el reverso de las pinturas, sobre el soporte o el bastidor. Un cuarenta y dos por ciento (42.5\%) de los lienzos de todos los siglos viene acompañado de distintas inscripciones que pueden o no ser contemporáneas a la elaboración del cuadro. Esta investigación no ha podido abordar más que superficialmente el tema de las inscripciones, puesto que para hacer un estudio serio sería necesario cotejar el material pictórico, la caligrafía y el contenido de cada una. La aportación más relevante de este trabajo se refiere a los llamados "sellos" en los reversos de las pinturas, por lo que sólo se hará referencia a ellos.

Estas marcas están presentes en un $7.14 \%$ y $3.75 \%$ de los lienzos del siglo XVII y XVIII, respectivamente, con la posibilidad de que algunas de las inscripciones registradas por los restauradores como números y letras (un $40 \%$ del total de las pinturas), se traten también de estos registros o "sellos". Este tipo de inscripción, a pesar de no tratarse literalmente de sellos, se ha llamado así para definir un grupo de inscripciones con características comunes, como entrelazar letras y números y estilizar los caracteres S, M y N, como se muestra en la figura 6.
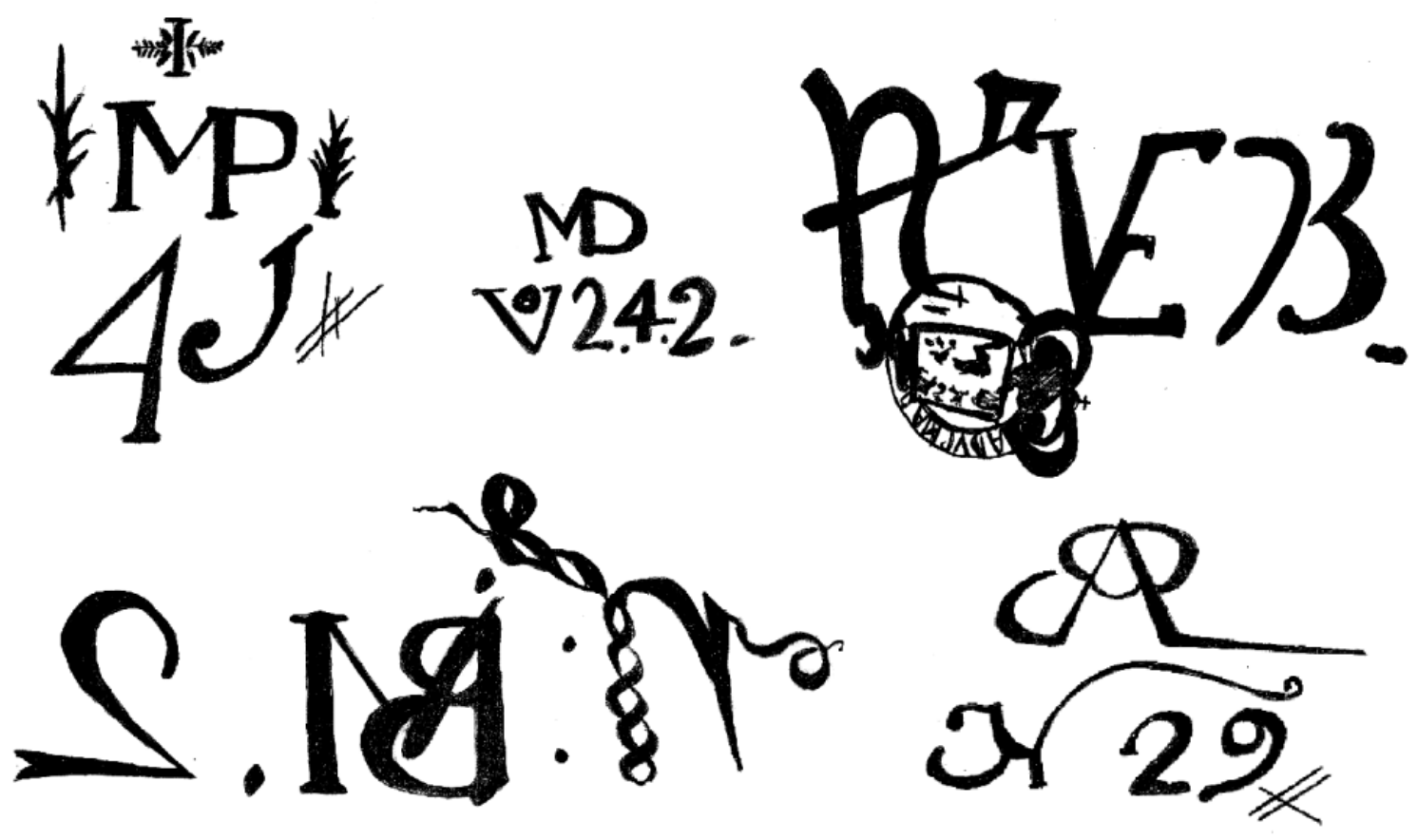

Figura 6. Diversas inscripciones consideradas "sellos" encontradas en soportes de las siguientes obras (de izquierda a derecha de arriba abajo): Desposorios de la Virgen, procedente del Seminario Arquidiocesano de Chihuahua, sellos "MP 4J" y "MD V242"; Fray Francisco de Jesús María, procedente del Convento de Guadalupe, Zacatecas, sello "NVEB"; El sueño de San José, procedente del museo regional de Tlaxcala, sello "NBM2" al revés; y Cristo renovado, procedente de Santuario Mapethé, Hidalgo, inscripción "AN29". Dibujos basados en fotografías de los informes: Autor. 


\section{Discusión}

La estructura del soporte determina en forma esencial la superficie de la pintura, cambia su brillo, color y textura, por lo que las consideraciones de tipo práctico no son suficientes para explicar, por ejemplo, la preferencia de un lienzo sobre una tabla, o de una tela de lino sobre una tela de seda. Los pintores saben -formal o intuitivamente- que las características de los soportes repercutirán en el resultado final de la obra, tanto en la imagen como en su estado de conservación, por lo que la elección de un soporte adecuado es resultado de una seria reflexión por parte del artista.

Las ordenanzas no especifican el material constitutivo del que debían estar hechos los soportes y, más bien, fueron los pintores los que buscaron asiduamente los lienzos de lino, a pesar de las dificultades que esto implicaba. De acuerdo con la opinión de algunos pintores encuestados a este respecto, el lino resulta ser una fibra idónea para formar soportes, pues casi no absorbe la pintura y mantiene un grado de fidelidad al trazo del artista que difícilmente se logra en lienzos de otras fibras. El lino es una fibra resistente que soporta las tensiones del montaje, mantiene sus dimensiones originales y no se deforma fácilmente. Esto explicaría cómo, durante cientos de años, los pintores estuvieron dispuestos a buscar tafetanes de lino a pesar de todas las dificultades que esto implicaba: la ausencia más o menos general de esta fibra en territorio americano, los escasos cultivos de lino en la península, los altos precios, los encargos a telares y trapiches, las telas reutilizadas e inclusive las importaciones ilegales (Sumano 2011:42- 50).

Todo lo anterior dio lugar a un contexto muy particular que se refleja tanto en la conformación de los lienzos, como en el modo en que fueron utilizados como soportes de pintura de caballete. Los resultados evidencian cómo la carestía de material obligaba a los pintores menos adinerados a incorporar recursos para aprovechar las telas al máximo: utilizaban pastas; dejaban pestañas muy pequeñas o inexistentes; se cosían varios fragmentos para formar lienzos de un tamaño útil y se reutilizaban textiles hechos con otro propósito. La práctica de reutilización de lienzos aparece reflejada en la documentación. En la Nueva España, las primeras ordenanzas de los pintores fueron presentadas ante el cabildo de la Ciudad de México el 30 de abril de 1557 y fueron confirmadas ese mismo año por el Virrey Luis de Velasco; en 1686 fueron reformadas y ratificadas por el Virrey Conde de Paredes Marqués de la Laguna. En estas ordenanzas se menciona la existencia de cuatro tipos de pintores: los imagineros, los doradores, los fresquistas y los sargueros. Las ordenanzas de los pintores abarcan una amplia gama de especificaciones, la mayoría destinadas a controlar la producción y evitar el comercio informal. Especifican también el tipo de exámenes y grados de los participantes del gremio, las habilidades que debían demostrar y los límites entre el oficio de un artesano y otro. En Otras ordenanzas de doradores y pintores, en 1557, se establece

"Que las imágenes que se hubieren de vender sean pintadas en lienzo nuevo cortado de la pieza, so pena de que al que labrare en lienzo viejo pierda las sargas, y más pague diez pesos aplicados como dicho es" (Barrio Lorenzot 1932: 20).

Como muestra este último párrafo, hacia finales del siglo XVI al cabildo le fue necesario especificar que no se debían usar lienzos viejos, debido a que esta práctica se había extendido entre los pintores por la falta de sargas, principalmente las hechas de lino. Con fecha 1686, y bajo el título Nuevas ordenanzas que siguen a las antecedentes de los pintores se especifica que:

"Ninguno pinte en lienzos viejos, ni en lienzos de China, sino sólo en lienzo crudo de Castilla nuevo y bien aparejado, so pena de perder la pintura aplicándola, como dicho es, y asimismo que ninguno dore, ni estofe si no fuere con muy buenos materiales de Castilla pena de veinte pesos como dicho es" (Barrio Lorenzot 1932: 24). 
El sistema de organización de trabajo en los obrajes de paños españoles no era el mismo que el de la Nueva España; por lo que es posible inferir que cuando, por ejemplo, Francisco de Peñafiel dice en 1539 "que va a hacer en Puebla paños como en Segovia", no se está refiriendo a la forma de organización del trabajo, sino a la calidad del producto final (Viqueira y Urbiola 1990:61). De una forma análoga, es posible especular que cuando las ordenanzas indican que se usará "sólo lienzo crudo de Castilla nuevo y bien aparejado", se está hablando de la calidad del producto final y no de la procedencia del lienzo. Ya desde 1565 se había dispuesto por cédula real que, para tejer los paños, se siguieran las ordenanzas existentes en Castilla, "que sean tejidos, tundidos y señalados conforme está ordenado en el obraje y todo lo demás que a su fabricación, labor y comercio pertenece" (Barrio Lorenzot 1932: 20). Es importante recalcar que la provincia de Castilla prácticamente no producía lino y cáñamo, sin embargo sí manufacturaba géneros provenientes de otras provincias como Granada y Orihuela, e importaba también géneros extranjeros. El lino español rara vez se exportaba, puesto que las cosechas apenas eran suficientes para satisfacer la demanda local (Serrera Contreras 1974: 48).

Si bien el lino ha sido el protagonista en cuanto a la conformación del tejido se refiere, a la producción de pintura de caballete mexicana también se incorporan otras fibras provenientes de cosechas locales, lo que se puede constatar en el material de algunos lienzos y sus costuras de unión. En Otras ordenanzas de sayaleros (1721) se documenta la existencia de una producción textil indígena que se manejaba en forma independiente de los obrajes y los gremios, y que utilizaba las fibras nativas como principal material para sus textiles. Un tipo de hilo muy particular utilizado en la unión de los lienzos del siglo XVII y XVIII es aquél que combina seda y algodón. La industria sericícola se implantó en la Nueva España temprana y exitosamente, pero su cultivo fue prohibido en 1596, cuando el virrey Conde de Monterrey recibe la orden de impedir la resiembra de vid, seda, cáñamo, lino y olivo, entre otros, intentando así proteger al mercado peninsular. Esto provocó que muchos de los cultivadores de seda se inclinaran por el algodón o incluso mezclaran ambas fibras.

La escasez de lienzos y la preferencia por aquellos de lino, deja constancia en la presencia de los "agujeros pareados". Debido a que la existencia de agujeros en un soporte no es algo deseable, es viable postular que indican carestía de material o falta de recursos. Es posible asumir que dichos lienzos se traten de reutilizaciones de telas que tuvieron otro propósito, como las velas para embarcaciones o molinos de viento, que en España solían hacerse de lino (Rojas Sola: 2010). Estos mismos agujeros se han identificado en textiles que no son soportes de pinturas, como en un forro de un estandarte textil jesuita del siglo XVII-XVIII, proveniente de Cusarare, Chihuahua, restaurado en el Seminario Taller de Restauración de Textiles de la ENCRyM. Esto reforzaría la teoría de que los agujeros son consecuencia de una práctica de reutilización que no se circunscribe a la creación de pintura de caballete, sino que responde a la carestía de lienzos de lino en México. Así mismo, en sólo cinco casos, los cuadros con agujeros pareados son de autor o se encuentran firmados, el resto se trata de cuadros de autor desconocido y factura más bien popular, lo que refuerza la hipótesis sobre la carestía de material, especialmente en centros rurales no regulados por los gremios.

Hoy en día, estos agujeros siguen provocando problemas de conservación que los restauradores mexicanos han subsanado con el uso de pastas compuestas de fibras de lino aglutinadas con gacha, para rellenar los agujeros y crear una superficie estable.

Por otro lado, es posible que la escasez de lienzos y las actividades al margen de las ordenanzas hayan provocado también la necesidad de aumentar el control gremial. Hacia 1540 la producción textil en la Nueva España debió haber crecido significativamente, pues las primeras normas de calidad fueron puestas en marcha; se pidió que: 
"los veedores tengan cuidado de que no salga de esta Ciudad, ninguna pieza de sayal o jerga sin estar sellada con el sello de la Ciudad, so pena de diez pesos por cada pieza que sellaren sin la dicha ley por la primera vez, y por la segunda privación de oficio por diez años" y "Que los veedores y selladores registren, y vean los sayales y jergas que vinieron de fuera, y estando conforme a esta ordenanza los marquen y no lo estando impidan su venta y los denuncien a los fieles ejecutores" (Barrio Lorenzot 1932:63).

También se determinó que:

“(...) los paños que se hacen en esta ciudad [de México] se haga un sello como los que se acostumbra hacer para sellar todos los paños que se hicieren en esta ciudad para que se sellen con él, y no se puedan vender otra manera so las penas de la pragmática que sobre ello hablan" (Barrio Lorenzot 1932:63).

En ese mismo año las Actas de Cabildo reiteran que "(...) está hecha una marca para marcar los paños que en esta ciudad se hicieren" (Actas de cabildo de la Ciudad de México 1540-43). Si bien los paños se "sellaban" con la idea de reglamentarlos, al parecer cada veedor tenía su marca particular. Una actividad análoga podría ser el marcaje de piezas metálicas hispanoamericanas, donde se pueden identificar varias marcas diferentes: de autor, de localidades, del ensayador o el impuesto fiscal o quinto. A pesar de los múltiples intentos por ordenarlas y regularizarlas, la práctica pocas veces siguió a la teoría, haciendo del marcaje un tema amplio y complejo que aún debe ser investigado.

\section{Conclusiones}

Puesto que el lino fue la fibra textil más usada para conformar los soportes textiles de las pinturas de caballete mexicanas de los siglos XVII al XIX y el acceso a esta fibra era muy limitado, en el territorio mexicano se fomentó una circunstancia particular entre los pintores, que hicieron grandes esfuerzos por obtener tafetanes de lino durante cientos de años. Este esfuerzo es aún visible en los soportes textiles de las pinturas de caballete, que evidencian a través de su materialidad la carestía lienzos y los recursos utilizados para subsanarla.

Existieron características comunes a todos los siglos, como la forma de unir el lienzo al bastidor con cola animal, seguida del uso de elementos metálicos, cuya presencia aumenta conforme pasa el tiempo. También durante todos los siglos, los pintores echaron mano de recursos que permitían compensar la carestía de material, como hacer cuadros sin pestañas, reutilizar lienzos, usar pastas, unir varios lienzos o partes de ellos y coser las uniones con muy poco material sobrante. En este contexto, es viable postular que los pintores echaban mano de lienzos de lino elaborados con otro propósito, como los originalmente destinados para las aspas de los molinos de viento españoles o las velas de las embarcaciones.

Nuevas líneas de investigación pueden abrirse basadas en el estudio de los soportes textiles de las pinturas de caballete en México. Por ejemplo, las diversas inscripciones que presentan los lienzos tanto coloniales como decimonónicos merecen un estudio detallado que correlacione los tipos de tinta utilizada, la caligrafía, el contenido de las inscripciones, su ubicación y su forma.

Al entender la importancia de la evidencia contenida en los soportes textiles de las pinturas de caballete, se ayuda a comprender los alcances de una intervención que modifique las características originales de la obra; así como el valor del registro que se lleva a cabo de ellas. El conflicto entre la restauración como una actividad técnica y la restauración como una disciplina antropológi- 
$\mathrm{ca} /$ científica reside en el apropiado registro e interpretación de los datos obtenidos de la obra. No sólo es necesario atender la materialidad del objeto, sino registrar y derivar de ésta, información útil para el entendimiento de la obra y de su historia.

\section{Glosario}

-Agujeros pareados: agujeros dispuestos en simetría en espejo, presentes en los lienzos de los cuadros del siglo XVII y XVIII, que resultan de la reutilización de lienzos de lino usados originalmente con otro propósito.

-Costura enrollada: forma de unión de las partes que componen al soporte de un cuadro, donde se enrollan sobre sí los sobrantes de las telas, ocupando distintos tipos de puntadas para asegurar la unión.

-Costura simple: forma de unión de las partes que componen al soporte de un cuadro, donde se toman los sobrantes de las telas y se costuran por su base, formando una unión con apariencia labiada.

-Densidad de tejido: número de hilos por centímetro cuadrado.

-Empalme de telas: forma de unión de las partes que componen al soporte de un cuadro, donde se empalman dos telas una sobre otra. La unión no lleva costuras, pero se refuerza con algún adhesivo.

-Ligamento textil: se refiere a la forma en la que se entrecruzan los hilos de la trama y de la urdimbre para formar una tela

-Pastas originales: recurso que utilizaron los pintores para extender la superficie pictórica más allá de los límites del lienzo; pegando el textil al canto frontal del bastidor y rellenando la ampliación con el mismo material con que se elaboraba la base de preparación.

-Sarga: ligamento textil donde los hilos de urdimbre y trama hacen bastas por encima de dos o más hilos de la dirección opuesta, en una progresión regular hacia la derecha o hacia la izquierda. Término que a veces se hace extensivo a toda la pintura sobre tela. En documentación antigua, este término significa también lienzo o tela.

-Tafetán: ligamento textil donde cada hilo de urdimbre se entrelaza con cada uno de los hilos de trama.

\section{Bibliografía}

BARRIO LORENZOT, F., comp. (1932). Ordenanzas de gremios de la Nueva España. México: Secretaría de Gobernación-Dirección de Talleres Gráficos.

BRUQUETAS GALÁN, R. (2007). Técnicas y materiales de la pintura española en los Siglos de Oro, $2^{\mathrm{a}}$ ed. $1^{\text {a }}$ reimpr. Madrid: Fundación de Apoyo a la Historia del Arte Hispánico.

Ciudad de México, Archivo Histórico de la Ciudad de México, Actas de cabildo de la Ciudad de México. (1543-44 Vol. IV, 9 de marzo de 1543).

DÁVILA LORENZANA, L. (2001). Oración del Huerto. Informe de trabajo STRPC-ENCRyM-INAH, México, s/ed.

ESTERAS MARTÍN, C. (1992). Marcas de platería hispanoamericana, siglos XVI-XX. Madrid: Ediciones Tuero.

GONZÁLEZ ANGULO, J. (1983). Artesanado y ciudad a finales del siglo XVIII. México: FCE.

GUZMÁN SOLANO, M. (1999). Informe de los trabajos realizados en la obra titulada: La Justicia Divina: Titulo adecuado: La Fe. Informe de trabajo STRPC-ENCRyM-INAH, México, s/ed. 
KHULIGER MARTíNEZ, V. (2003). Informe del trabajo realizado a la obra inmaculada procedente de la Parroquia de San Francisco, Pinos, Zacatecas. Informe de trabajo STRPC-ENCRyM-INAH, México, s/ed.

KOLLER, M. (1984). "Das Staffeleibild der Neuzeit". En Reclams Handbuch der künstlerischen Techniken, Tomo I, Stuttgart: Philipp Reclam, 261-464.

LAURENBACHER, K. (2005). "Reentelados, parches y remiendos. Mucha tela". En Interim meeting: International Conference on painting conservation. Canvases: behavior, deterioration \& treatment. Valencia, Universidad Politécnica de Valencia: 11-119.

MIÑO GRIJALVA, M. (1993). La protoindustria colonial hispanoamerican. México: FCE.

ROJAS MUÑOZ, C. (1999) Informe final de los trabajos realizados en la obra. Virgen con niño -La Caridad. Informe de trabajo STRPC-ENCRyM-INAH, México: s/ed.

ROJAS SOLA, J.I. (2010). Comunicación escrita, Departamento de Ingeniería Gráfica, Diseño y Proyectos de la Universidad de Jaén, España.

SERRERA CONTRERAS, R. (1974). Cultivo y manufactura de lino y cáñamo en Nueva España (1777-1800). Sevilla: Escuela de estudios Hispano Americanos de Sevilla, Consejo Superior de Investigaciones Científicas.

STRAUB, R. (1984) "Tafel- und Tüchleinmalerei des Mittelalters". En Reclams Handbuch der künstlerischen Techniken, Tomo I, Stuttgart: Philipp Reclam, 131-259.

SUMANO GONZÁLEZ, R. (2010). Estudio de la técnica de factura de los soportes textiles de la pintura de caballete en México, siglos XVII al XIX, tesis de Licenciatura en Restauración, México, ENCRYM-INAH.

SUMANO GONZÁLEZ, R. (2011). “Los soportes textiles de las pinturas mexicanas: estudio estadístico e histórico". En Revista Intervención, México: INAH, Año 2, No. 3: 43-50.

http://www.ilam.org/ILAMDOC/edu/Revista\%20Intervencion.3.0.pdf.

VEIGA DE OLIVEIRA, E., GLAHANO, F. et. al. (1978). Tecnologia tradicional portuguesa: o linho. Lisboa: Instituto Nacional de Investigação Científica-Centro de Estúdios de Etnologia.

VIQUEIRA, C. y URQUIOLA, J. (1993). Los obrajes en la Nueva España, 1530-1630. México: CONACULTA.

VV.AA. (1995). Lining and Backing: the Support of Paintings, Paper and Textiles. UKIC Conference 7-8 Noviembre, Londres: UKIC.

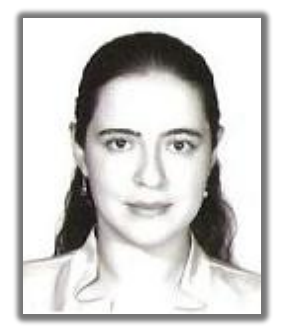

Rita Sumano González

ritasumano@hotmail.com

Licenciada en Restauración por la ENCRyM-INAH y Maestra en Tasación de Arte y Antigüedades por la UAH. Beneficiaria del Programa de Becas Para Estudios en el Extranjero del FONCA-CONACyT (2010-2012) y premio INAH a la mejor tesis de licenciatura en conservación (2011).

Artículo recibido el 03/05/2012

Artículo aceptado el 13/07/2012 